\title{
CD4 Count of Art and Non-Art Hiv Positive Patients Attending Living Word Mission Hospital Abayi Aba, Abia State, Nigeria
}

\author{
*Obeagu Emmanuel Ifeanyi ${ }^{1}$, Okoroiwu Ijeoma Leticia ${ }^{2}$, Ochei Kingsley \\ Chinedum $^{3}$, Okoro Nnenna Kalu ${ }^{4}$, Udenze Chikwendu Lawrence ${ }^{5}$ \\ 1.Diagnostic Laboratory Unit,University Health Services Department,Michael Okpara University of \\ Agriculture,Umudike, Abia State, Nigeria. \\ 2 Lecturer, Department of Medical Laboratory Science, Faculty of Health Sciences, Imo State \\ University, Owerri, Nigeria. \\ 3.H.S.S and Laboratory Department, FHI 360,Country Office, Plot 1073-A1,Garki,Abuja, FCT,Nigeria. \\ 4.Laboratory Department, Living Word Mission Hospital,5-7 Abayi Road,Aba,Abia State, Nigeria. \\ 5.Medical Doctor,University Health Services Department, Michael Okpara University of Agriculture,Umudike, \\ Abia State, Nigeria.
}

\begin{abstract}
The study was carried out in Living Word Mission Hospital, Abayi, Aba, Abia State, Nigeria.The study was carried out among the ART and non-ART HIV patients attending the hospital.The CD4 count values were compared among the ART and the non-ART HIV patients to ascertain if there is any significant change among those on treatment and those not receiving treatment. The total number of subjects for the study was 97 (female $=68$, male $=29) .77$ subjects were ART HIV patients (female $=55$ and male=22) while 20 subjects were non-ART HIV patients (female $=14$ and male=6). The study showed significant increase $(P<0.05)$ in the CD4 count of ART HIV patients more than non-ART HIV patients. The study equally showed significant increase $(P<0.05)$ among the female ART HIV patients compared to the male ART HIV patients. The study showed that CD4 count should be done early to know when to start the treatment and the antiretroviral drugs have significant improvement in the immune system of the patients particularly the females.
\end{abstract}

Keywords: CD4 Count, ART HIV Patients, Non-ART HIV Patients, HIV, Antiretroviral Therapy(ART).

\section{Introduction}

The human immunodeficiency virus (HIV) is a lentivirus (slowly replicating that causes the acquired immunodeficiency syndrome (AIDS) (Weiss,1993;Douek et al.,2009) a condition in humans in which progressive failure of the immune system allows life-threatening opportunistic infections and cancers to thrive. Infection with HIV occurs by the transfer of blood, semen, vaginal fluid, pre-ejaculate, or breast milk. Within these bodily fluids, HIV is present as both free virus particles and virus within infected immune cells.

$\mathrm{HIV}$ infects vital cells in the human immune system such as helper T cells (specifically $\mathrm{CD} 4^{+} \mathrm{T}$ cells), macrophages, and dendritic cells (Cunningham et al., 2010). HIV infection leads to low levels of CD4 ${ }^{+} \mathrm{T}$ cells through a number of mechanisms including: apoptosis of uninfected bystander cells (Garg et al., 2012), direct viral killing of infected cells, and killing of infected $\mathrm{CD} 4^{+} \mathrm{T}$ cells by $\mathrm{CD} 8$ cytotoxic lymphocytes that recognize infected cells (Kumar, 2102). When $\mathrm{CD}^{+} \mathrm{T}$ cell numbers decline below a critical level, cell-mediated immunity is lost, and the body becomes progressively more susceptible to opportunistic infections.

Lentiviruses are transmitted as single-stranded, positive-sense, enveloped RNA viruses. Upon entry into the target cell, the viral RNA genome is converted into double-stranded DNA by a virally encoded reverse transcriptase that is transported along with the viral genome in the virus particle. The resulting viral DNA is then imported into the cell nucleus and integrated into the cellular DNA by a virally encoded integrase and host cofactors (Smith and Daniel, 2006). Once integrated, the virus may become latent, allowing the virus and its host cell to avoid detection by the immune system. Alternatively, the virus may be transcribed, producing new RNA genomes and viral proteins that are packaged and released from the cell as new virus particles that begin the replication cycle anew.

HIV can infect a variety of immune cells such as $\mathrm{CD} 4^{+} \mathrm{T}$ cells, macrophages, and microglial cells. HIV-1 entry to macrophages and $\mathrm{CD}^{+}{ }^{+} \mathrm{T}$ cells is mediated through interaction of the virion envelope glycoproteins (gp120) with the CD4 molecule on the target cells and also with chemokine coreceptors(Chan et al.,1997).

Macrophage (M-tropic) strains of HIV-1, or non-syncitia-inducing strains (NSI; now called R5 viruses (Berger et al., 1998) use the $\beta$-chemokine receptor CCR5 for entry and are, thus, able to replicate in macrophages and $\mathrm{CD}^{+} \mathrm{T}$ cells (Coakley et al.,1996). This CCR5 coreceptor is used by almost all primary HIV-1 isolates regardless of viral genetic subtype. Indeed, macrophages play a key role in several critical aspects of HIV 
infection. They appear to be the first cells infected by HIV and perhaps the source of HIV production when $\mathrm{CD}^{+}$cells become depleted in the patient. Macrophages and microglial cells are the cells infected by HIV in the central nervous system. In tonsils and adenoids of HIV-infected patients, macrophages fuse into multinucleated giant cells that produce huge amounts of virus.

T-tropic isolates, or syncitia-inducing (SI; now called X4 viruses (Berger et al.,1998) strains replicate in primary $\mathrm{CD}^{+} \mathrm{T}$ cells as well as in macrophages and use the $\alpha$-chemokine receptor, CXCR4, for entry.(Coakley et al ., 2005; Deng et al.,1996; Feng et al.,1996). Dual-tropic HIV-1 strains are thought to be transitional strains of HIV-1 and thus are able to use both CCR5 and CXCR4 as co-receptors for viral entry.

The $\alpha$-chemokine SDF-1, a ligand for CXCR4, suppresses replication of T-tropic HIV-1 isolates. It does this by down-regulating the expression of CXCR4 on the surface of these cells. HIV that use only the CCR5 receptor are termed R5; those that use only CXCR4 are termed X4, and those that use both, X4R5. However, the use of coreceptor alone does not explain viral tropism, as not all R5 viruses are able to use CCR5 on macrophages for a productive infection (Coakley et al.,2005) and HIV can also infect a subtype of myeloid dendritic cells,(Knight et al.,1990) which probably constitute a reservoir that maintains infection when $\mathrm{CD}^{+} \mathrm{T}$ cell numbers have declined to extremely low levels.

Some people are resistant to certain strains of HIV. (Tang and Kaslow, 2003). For example, people with the CCR5- $\triangle 32$ mutation are resistant to infection with R5 virus, as the mutation stops HIV from binding to this coreceptor, reducing its ability to infect target cells.

Sexual intercourse is the major mode of HIV transmission. Both X4 and R5 HIV are present in the seminal fluid, which is passed from a male to his sexual partner. The virions can then infect numerous cellular targets and disseminate into the whole organism. However, a selection process leads to a predominant transmission of the R5 virus through this pathway. (Zhu et al.,1993; Vant't Wout et al.,1994; Zhu et al.,1996) How this selective process works is still under investigation, but one model is that spermatozoa may selectively carry R5 HIV as they possess both CCR3 and CCR5 but not CXCR4 on their surface (Muciaccia et al.,2005) and that genital epithelial cells preferentially sequester X4 virus. (Berlier et al.,2005). In patients infected with subtype B HIV-1, there is often a co-receptor switch in late-stage disease and T-tropic variants appear that can infect a variety of $\mathrm{T}$ cells through CXCR4 (Clevestig et al., 2005) These variants then replicate more aggressively with heightened virulence that causes rapid $\mathrm{T}$ cell depletion, immune system collapse, and opportunistic infections that mark the advent of AIDS (Moore,1997). Thus, during the course of infection, viral adaptation to the use of CXCR4 instead of CCR5 may be a key step in the progression to AIDS. A number of studies with subtype B-infected individuals have determined that between 40 and 50 percent of AIDS patients can harbour viruses of the SI and, it is presumed, the X4 phenotypes(Karlsson et al.,1994;Koot et al.,1996)

HIV-2 is much less pathogenic than HIV-1 and is restricted in its worldwide distribution. The adoption of "accessory genes" by HIV-2 and its more promiscuous pattern of coreceptor usage (including CD4independence) may assist the virus in its adaptation to avoid innate restriction factors present in host cells. Adaptation to use normal cellular machinery to enable transmission and productive infection has also aided the establishment of HIV-2 replication in humans. A survival strategy for any infectious agent is not to kill its host but ultimately become a commensal organism. Having achieved a low pathogenicity, over time, variants more successful at transmission will be selected(Cheney and McKnight,2010)

$\mathrm{HIV}$ enters macrophages and $\mathrm{CD} 4^{+} \mathrm{T}$ cells by the adsorption of glycoproteins on its surface to receptors on the target cell followed by fusion of the viral envelope with the cell membrane and the release of the HIV capsid into the cell(Chan and Klim,1998; Wyatt et al.,1998)

Entry to the cell begins through interaction of the trimeric envelope complex (gp160 spike) and both CD4 and a chemokine receptor (Chan and Klim,1998;Wyatt et al.,1998) generally either CCR5 or CXCR4, but others are known to interact) on the cell surface gp120 binds to integrin $\alpha_{4} \beta_{7}$ activating LFA-1 the central integrin involved in the establishment of virological synapses, which facilitate efficient cell-to-cell spreading of HIV-1(Arthros et al.,2008). The gp160 spike contains binding domains for both CD4 and chemokine receptors(Chan and Klim,1998; Wyatt et al.,1998).

The first step in fusion involves the high-affinity attachment of the CD4 binding domains of gp120 to CD4. Once gp120 is bound with the CD4 protein, the envelope complex undergoes a structural change, exposing the chemokine binding domains of gp120 and allowing them to interact with the target chemokine receptor(Chan and Klim,1998; Wyatt et al.,1998). This allows for a more stable two-pronged attachment, which allows the N-terminal fusion peptide gp41 to penetrate the cell membrane(Chan and Klim,1998; Wyatt et al.,1998). Repeat sequences in gp41, HR1, and HR2 then interact, causing the collapse of the extracellular portion of gp41 into a hairpin. This loop structure brings the virus and cell membranes close together, allowing fusion of the membranes and subsequent entry of the viral capsid(Chan and Klim,1998; Wyatt et al.,1998).

After HIV has bound to the target cell, the HIV RNA and various enzymes, including reverse transcriptase, integrase, ribonuclease, and protease, are injected into the cell( Chan and Klim,1998). During the 
microtubule-based transport to the nucleus, the viral single-strand RNA genome is transcribed into doublestrand DNA, which is then integrated into a host chromosome.

HIV can infect dendritic cells (DCs) by this CD4-CCR5 route, but another route using mannosespecific C-type lectin receptors such as DC-SIGN can also be used(Pope and Haase,2003). DCs are one of the first cells encountered by the virus during sexual transmission. They are currently thought to play an important role by transmitting HIV to T-cells when the virus is captured in the mucosa by DCs (Chan and Klim,1998). The presence of FEZ-1, which occurs naturally in neurons, is believed to prevent the infection of cells by HIV(Haedicke et al.,2009).

In molecular biology, CD4 (cluster of differentiation 4) is a glycoprotein found on the surface of immune cells such as $\mathrm{T}$ helper cells, monocytes, macrophages, and dendritic cells. It was discovered in the late 1970s and was originally known as leu-3 and T4 (after the OKT4 monoclonal antibody that reacted with it) before being named CD4 in 1984(Alain,1984). In humans, the CD4 protein is encoded by the CD4 gene(Isobe et al.,1986; Ansari-Lari et al.,1996).

CD4+ T helper cells are white blood cells that are an essential part of the human immune system. They are often referred to as CD4 cells, T-helper cells or T4 cells. They are called helper cells because one of their main roles is to send signals to other types of immune cells, including CD8 killer cells. CD4 cells send the signal and CD8 cells destroy the infectious particle. If CD4 cells become depleted, for example in untreated HIV infection, or following immune suppression prior to a transplant, the body is left vulnerable to a wide range of infections that it would otherwise have been able to fight.

CD4 uses its $D_{1}$ domain to interact with the $\beta_{2}$-domain of MHC class II molecules. T cells expressing CD4 molecules (and not CD8) on their surface, therefore, are specific for antigens presented by MHC II and not by MHC class I (they are MHC class II-restricted). MHC class I contains Beta-2 microglobulin.

The short cytoplasmic/intracellular tail (C) of CD4 contains a special sequence of amino acids that allow it to interact with the lck molecule.

CD4 is a co-receptor that assists the T cell receptor (TCR) in communicating with an antigenpresenting cell. Using its intracelluar domain, CD4 amplifies the signal generated by the TCR by recruiting an enzyme, the tyrosine kinase Lck, which is essential for activating many molecular components of the signaling cascade of an activated T cell. Various types of T helper cells are thereby produced. CD4 also interacts directly with MHC class II molecules on the surface of the antigen-presenting cell using its extracellular domain. The extracellular domain adopts an immunoglobulin-like beta-sandwich with seven strands in 2 beta sheets, in a Greek key topology(Brady et al.,1993).

HIV-1 uses CD4 to gain entry into host T-cells and achieves this through its viral envelope protein known as gp120(Kwong et al.,1998). The binding to CD4 creates a shift in the conformation of gp120 allowing HIV-1 to bind to a co-receptor expressed on the host cell. These co-receptors are chemokine receptors CCR5 or CXCR4. Following a structural change in another viral protein (gp41), HIV inserts a fusion peptide into the host cell that allows the outer membrane of the virus to fuse with the cell membrane.

HIV infection leads to a progressive reduction in the number of T cells expressing CD4. Medical professionals refer to the CD4 count to decide when to begin treatment during HIV infection. Normal blood values are usually expressed as the number of cells per microliter (or cubic millimeter, $\mathrm{mm}^{3}$ ) of blood, with normal values for CD4 cells being $500-1200$ cells $/ \mathrm{mm}^{3(B o f i l ~ e t ~ a l ., 1992) . ~} A$ CD4 count measures the number of T cells expressing CD4. While CD4 counts are not a direct HIV test--e.g. they do not check the presence of viral DNA, or specific antibodies against HIV--they are used to assess the immune system of a patient. Patients often undergo treatments when the CD4 counts reach a level of 350 cells per microliter in Europe but usually around $500 \mathrm{cpm}$ in the US; people with less than 200 cells per microliter are at high risk of contracting AIDS defined illnesses. The newest National Institute of Health guidelines recommend treatment of any HIV-positive individuals, regardless of CD4 count. Medical professionals also refer to CD4 tests to determine efficacy of treatment.

\section{Materials And Methods}

Study Area:The sudy was done in Living Word Mission Hospital, Abayi, Aba, Abia State, Nigeria.

Subjects: 97 HIV subjects were used for the study (female $=68$ and male $=29$ ) who attended Living Word Mission Hospital Abayi, Aba, Abia State. 77 subjects were on $\mathrm{ART}(\mathrm{female}=55$, male $=22)$ and 20 subjects were non-ART HIV patients (female $=14$ and male $=6$ ).

Sample and methods: Venous blood samples were collected from the subjects into EDTA anticoagulated blood containers for the CD4 count.

Statistical Analysis:The data were analysed with t-test and statistical significance set at $\mathrm{P}<0.05$.

Ethics:Oral consents were made to the subjects prior to the sample collection. 


III. Results
Table 1:Cd4 Count Among Art And Non-Art Hiv Positive Patients
\begin{tabular}{|l|l|l|}
\hline ART & NON-ART & Significance level \\
\hline $541 \pm 20$ & $395 \pm 15$ & $\mathrm{P}<0.05$ \\
\hline
\end{tabular}

KEYS:ART=Antiretroviral Therapy

Table 2:Cd Count In Hiv Positive Patients On Art Based On Gender

\begin{tabular}{|l|l|l|}
\hline MALE & FEMALE & Significance level \\
\hline $457 \pm 17$ & $518 \pm 20$ & $\mathrm{P}<0.05$ \\
\hline
\end{tabular}

Table 3:Cd 4 Count On Non-Art Hiv Positive Patients Based On Gender

\begin{tabular}{|l|l|l|}
\hline MALE & FEMALE & Significance level \\
\hline $260 \pm 13$ & $304 \pm 10$ & $\mathrm{P}<0.05$ \\
\hline
\end{tabular}

Table 4:Cd4 Count Among Female Art And Non-Art Hiv Positive Patients

\begin{tabular}{|l|l|l|}
\hline ART & NON-ART & Significance level \\
\hline $518 \pm 19$ & $304 \pm 21$ & $\mathrm{P}<0.05$ \\
\hline
\end{tabular}

Table 5:Cd4 Count Among Male Art And Non-Art Hiv Positive Patients

\begin{tabular}{|l|l|l|}
\hline ART & NON-ART & Significance level \\
\hline $457 \pm 12$ & $260 \pm 15$ & $\mathrm{P}<0.05$ \\
\hline
\end{tabular}

\section{Discussion}

HIV is a multisystemic infection that suppresses haematopoietic system (Obeagu et al., 2014). HIV/AIDS is a a gradual silent killer.The greatest problem with HIV/AIDS menance is that most people infected do not know and many are afraid to go for test and its associated stigma to know their status thereby affecting many people (Obeagu et al., 2014). HIV is a retrovirus that causes Acquired Immunodeficiency Virus Syndrome (AIDS) (Weiss, 1993 and Douk et al.,2009), a condition in humans in which progressive failure of the immune system allows life-threatening opportunistic infections and cancers to thrive.Infection with HIV occurs by the transfers of blood,semen, vaginal fluids. HIV is present as both free virus particles and virus within infected immune cell.

HIV infects vital cells in the human immune sysytem such as helper T-cells(especially CD4 Tcells),macrophages, and dentritic cells (Cunningham et al., 2010). HIV infection leads to low levels of CD4 T cells through a number of mechanisms including apoptosis of uninfected bystander cells (Garg et al., 2012), direct viral killing of infected cells, and killing of infected CD 4 T cells by CD4 T cells cytotoxic lymphocytes that recognise infected cells (Kumar,2012). When CD4 Tcells number decline below a critical level,cellmediated immunity is lost and the body becomes progressively more susceptible to opportunistic infection.

Table 1 showed significant increase $(\mathrm{P}<0.05)$ when the mean values of $\mathrm{CD} 4$ count of ART HIV patients were compared with the mean values of CD4 count of the non-ART HIV positive patients. This could be as a result of improvement in the immune sysytem of the HIV positive patients receiving treatment which is determined by measuring the CD4 count which is a major immune arm. This points out that early detection of the infection is very important to boost the immune level by placing the patient on ART on time to reinforce the CD4 level thereby improving the general well-being of the patients.

Table 2 showed significant increase $(\mathrm{P}<0.05)$ when the mean values of CD4 count of females was compared to the mean values of CD4 of males on ART.This shows that women respond faster to the effect of the drug thereby having more robust immune improvement compared to their male counterpart.This may be that the females adhere to the instructions(compliance) tenaciously more than their male couterpart.Females may take more precautionary measures more than the males who may expose themselves to more dangerous behaviours such as excessive alcohol intake,smoking and illicit unprotected sex with HIV positive patients with high virulence strains.

Table 3 showed significant increase $(\mathrm{P}<0.05)$ in the mean values of CD4 count of females compared to the mean values of CD4 count of males who were non-ART HIV positive patients. This significant difference could be traceable to menstruation by the females which reduces viral load.

Table 4 showed significant increase in the CD4 count of females on $\operatorname{ART}(<0.05)$ compared to the CD4 count of female non-ART HIV patients. This shows improvement in the immune system of those HIV patients on ART unlike those not receiving treatment.

Table 5 showed significant increase $(\mathrm{P}<0.05)$ in the mean CD4 count of male on ART HIV patients compared to the mean values of CD4 count non-ART HIV male patients. The study showed significant 
improvement in the immune system of the HIV patient placed on ART.The study shows that antiretroviral therapy plays a significant role in the general well-being of those infected with HIV.

\section{Conclusion}

The study showed significant increase in the CD4 count of the ART HIV patients more than the nonART HIV patients. This shows that it is important to know your HIV status on time and to monitor the level CD4 $\mathrm{T}$ cells level to start ART early enough to ensure improved well-being of the infected patients. There was more significant improvement in the females placed on ART more than their male counterparts.More enlightment campaign should be carried out to the populace for adequate health education to start the treatment early to prolong the life span and happines of those infected with HIV.Compliance to the treatment is important to ensure that the efficacy of these drugs are utilised.

\section{Refernces}

[1]. Weiss, R.A. ( 1993). "How does HIV cause AIDS?". Science 260 (5112): 1273-9.

[2]. Douek, D.C., Roederer, M.,and Koup, R.A. (2009). "Emerging Concepts in the Immunopathogenesis of AIDS". Annu. Rev. Med. 60: $471-84$.

[3]. Cunningham, A.; Donaghy, H.; Harman, A.; Kim, M.;and Turville, S. (2010). "Manipulation of dendritic cell function by viruses". Current opinion in microbiology 13 (4): 524-529.

[4]. Garg, H; Mohl, J; Joshi, A (, 2012). "HIV-1 induced bystander apoptosis.". Viruses 4 (11): 3020-43.

[5]. Kumar, V. (2012). Robbins Basic Pathology (9th ed.). p. 147.

[6]. Smith, J.A, and Daniel, R. (2006). "Following the path of the virus: the exploitation of host DNA repair mechanisms by retroviruses". ACS Chem Biol 1 (4): 217-26..

[7]. Chan, D.C., Fass, D., Berger, J.M.,and Kim, P.S. (1997). "Core structure of gp41 from the HIV envelope glycoprotein". Cell 89 (2): 263-73.

[8]. Berger, E. A.; Doms, R. W.; Fenyö, E. -M.; Korber, B. T. M.; Littman, D. R.; Moore, J. P.; Sattentau, Q. J.; Schuitemaker, H.; Sodroski, J.; Weiss, R. A. (1998). "A new classification for HIV-1". Nature 391 (6664): 240.

[9]. Coakley, E., Petropoulos, C.J.,and Whitcomb, J.M. (2005). "Assessing ch vbgemokine co-receptor usage in HIV". Current Opinion in Infectious Diseases 18 (1): 9-15.

[10]. Deng, H., Liu, R., Ellmeier, W., Choe, S., Unutmaz, D., Burkhart, M., Di Marzio, P., Marmon, S., Sutton, RE., Hill, C.M., Davis, C.B., Peiper, S.C., Schall, T.J., Littman, D.R., Landau, N.R; Liu; E; Choe; U; Burkhart; M; Marmon; S; Hill; D et al. (1996). "Identification of a major co-receptor for primary isolates of HIV-1". Nature 381 (6584): 661-6.

[11]. Feng, Y., Broder, C.C., Kennedy, P.E., Berger, E.A; and Broder; K. B. (1996). "HIV-1 entry cofactor: functional cDNA cloning of a seven-transmembrane, G protein-coupled receptor". Science 272 (5263): 872-7.

[12]. Knight, S.C., Macatonia, S.E. and Patterson, S. (1990). "HIV I infection of dendritic cells". International Review of Immunology 6 (2-3): $163-75$

[13]. Tang, J., Kaslow, R.A. (2003). "The impact of host genetics on HIV infection and disease progression in the era of highly active antiretroviral therapy". AIDS 17 (Suppl 4): S51-S60.

[14]. Zhu, T., Mo, H, Wang, N., Nam, D.S., Cao, Y., Koup, R.A., Ho, D.D; Mo; W; Nam, C. and Koup, H. (1993). "Genotypic and phenotypic characterization of HIV-1 patients with primary infection". Science 261 (5125): 1179-81.

[15]. van’t Wout, A.B., Kootstra, N.A., Mulder-Kampinga, G.A., Albrecht-van Lent, N., Scherpbier, H.J., Veenstra, J., Boer, K., Coutinho, R.A., Miedema, F. and Schuitemaker, H. (1994). "Macrophage-tropic variants initiate human immunodeficiency virus type 1 infection after sexual, parenteral, and vertical transmission". J Clin Invest 94 (5): 2060-7.

[16]. Zhu, T., Wang, N., Carr, A., Nam, D.S., Moor-Jankowski, R., Cooper, D.A. and Ho, D.D. (1996). "Genetic characterization of human immunodeficiency virus type 1 in blood and genital secretions: evidence for viral compartmentalization and selection during sexual transmission". J Virol 70 (5): 3098-107.

[17]. Muciaccia, B., Padula, F., Vicini, E., Gandini, L., Lenzi, A. and Stefanini, M. (2005). "Beta-chemokine receptors 5 and 3 are expressed on the head region of human spermatozoon". FASEB J 19 (14): 2048-50.

[18]. Berlier, W., Bourlet, T., Lawrence, P., Hamzeh, H., Lambert, C., Genin, C., Verrier, B., Dieu-Nosjean, M.C., Pozzetto, B. and Delezay, O. (2005). "Selective sequestration of X4 isolates by human genital epithelial cells: Implication for virus tropism selection process during sexual transmission of HIV". J Med Virol. 77 (4): 465-74.

[19]. Clevestig, P., Maljkovic, I., Casper, C., Carlenor, E., Lindgren, S., Naver, L., Bohlin, A.B., Fenyo, E.M., Leitner, T. and Ehrnst, A. (2005). "The X4 phenotype of HIV type 1 evolves from R5 in two children of mothers, carrying X4, and is not linked to transmission". AIDS Res Hum Retroviruses 5 (21): 371-8.

[20]. Moore, J.P. (1997). "Coreceptors: implications for HIV pathogenesis and therapy". Science 276 (5309): 51-2.

[21]. Karlsson, A., Parsmyr, K., Aperia, K., Sandstrom, E., Fenyo, E.M. and Albert, J. (1994). "MT-2 cell tropism of human immunodeficiency virus type 1 isolates as a marker for response to treatment and development of drug resistance". J Infect Dis. 170 (6): 1367-75.

[22]. Koot, M., van 't Wout, A.B., Kootstra, N.A., de Goede, R.E., Tersmette, M. and Schuitemaker, H. (1996). "Relation between changes in cellular load, evolution of viral phenotype, and the clonal composition of virus populations in the course of human immunodeficiency virus type 1 infection". J Infect Dis. 173 (2): 349-54.

[23]. Cheney, K. and McKnight, A. (2010). "HIV-2 Tropism and Disease". Lentiviruses and Macrophages: Molecular and Cellular Interactions. Caister Academic Press.

[24]. Chan, D. and Kim, P. (1998). "HIV entry and its inhibition". Cell 93 (5): 681-4.

[25]. Wyatt, R., Sodroski, J. and Sodroski, (1998). "The HIV-1 envelope glycoproteins: fusogens, antigens, and immunogens". Science 280 (5371): 1884-8.

[26]. Arthos, J., Cicala, C., Martinelli, E., Macleod, K., Van Ryk, D., Wei, D., Xiao, Z., Veenstra, T.D., Conrad, T.P., Lempicki, R.A., McLaughlin, S., Pascuccio, M., Gopaul, R., McNally, J., Cruz, C.C., Censoplano, N., Chung, E., Reitano, K.N., Kottilil, S., Goode, D.J. and Fauci, A.S. (2008). "HIV-1 envelope protein binds to and signals through integrin alpha(4)beta(7), the gut mucosal homing receptor for peripheral T cells". Nature Immunology. In Press (3): 301-9.

[27]. Pope, M. and Haase, A. (2003). "Transmission, acute HIV-1 infection and the quest for strategies to prevent infection". Nat Med 9 (7): $847-52$. 
[28]. Haedicke, J.; Brown, C. and Naghavi, M. H. (Aug 2009). "The brain-specific factor FEZ1 is a determinant of neuronal susceptibility to HIV-1 infection". Proceedings of the National Academy of Sciences 106 (33): 14040-14045

[29]. Alain, B. (1984). Leucocyte typing: human leucocyte differentiation antigens detected by monoclonal antibodies: specification, classification, nomenclature: [report on the first international references workshop sponsored by INSERM, WHO and IUIS]. Berlin: Springer. pp. pages $45-48$

[30]. Isobe, M., Huebner, K., Maddon, P.J., Littman, D.R., Axel, R. and Croce, C.M. ( 1986). "The gene encoding the T-cell surface protein T4 is located on human chromosome 12". Proc. Natl. Acad. Sci. U.S.A. 83 (12): 4399-402.

[31]. Ansari-Lari, M.A., Muzny, D.M., Lu, J., Lu, F., Lilley, C.E., Spanos, S., Malley, T. and Gibbs, R.A. ( 1996). "A gene-rich cluster between the CD4 and triosephosphate isomerase genes at human chromosome 12p13". Genome Res. 6 (4): 314-26.

[32]. Brady, R.L., Dodson, E.J., Dodson, G.G., Lange, G., Davis, S.J., Williams, A.F. and Barclay, A.N. ( 1993). "Crystal structure of domains 3 and 4 of rat CD4: relation to the NH2-terminal domains". Science 260 (5110): 979-83.

[33]. Kwong, P.D., Wyatt, R., Robinson, J., Sweet, R.W., Sodroski, J. and Hendrickson, W.A. ( 1998). "Structure of an HIV gp120 envelope glycoprotein in complex with the CD4 receptor and a neutralizing human antibody". Nature 393 (6686): 648-59.

[34]. Obeagu,E.I.,Obarezi,T.N,Omeh,Y.N.,Okoro,N.K. and Eze,O.N.L,(2014).Assessement of Some Ha ematological and Biochemical Parameters in HIV Patients Before Receiving Treatment in Aba,Abia State,Nigeria.Research Journal of Pharmaceutical,Biological and Chemical Sciences 5(2):825-830. 